\title{
Perception of body image as indicator of weight status in the European Union
}

\author{
A. Sánchez-Villegas, ${ }^{*}$ H. Madrigal, †§ M. A. Martínez-González, ${ }^{*}$ J. Kearney, $\$$ M. J. Gibney, \\ J. de Irala* and J. A. Martínez§ \\ *Dpto.de Epidemiología y Salud Pública and §Dpto. Fisiología y Nutrición de la Universidad de Navarra, Irunlarrea s/n Pamplona \\ 31008, Spain; †Instituto Nacional de Nutrición 'Salvador Zubirán', Vasco de Quiroga 15 Tlalpan, México 14000 D.F. México; \\ †Institute of European Food Studies, Trinity College, Dublín 2, Ireland
}

\section{Correspondence}

Prof. Miguel A. Martínez-González

Unidad de Epidemiología y Salud

Pública de la Universidad de Navarra, Irunlarrea 1 ,

Pamplona 31008,

Spain.

Fax: +34 94842 56-49

E-mail: mamartinez@unav.es

\section{Keywords}

body image, European Union, weight status.

Accepted

January 2001

\begin{abstract}
Objective To identify the factors associated with an adequate perception of body image in relation to body weight.

Material and methods An observational, cross-sectional study was conducted in a representative sample of the European Union (7155 men and 8077 women). Body Mass Index (BMI) was grouped into four categories, perceived body image was assessed using the nine silhouettes drawing scheme. A multivariable logistic regression model for each sex was used to adjust for potentially confounding variables.
\end{abstract}

Results Underweight men and women classified themselves better than other groups (92.9\% of correct answers among men and 79.3\% among women). Overall, women classified themselves better than men $(57.6 \%$ vs. $32.7 \%)$.

Discussion Perceived body image as a method of assessment for body weight has different validity depending on sociodemographic or attitudinal categories. Perceived body image as an estimate of the nutritional status has a limited individualized application. Thus, perhaps it could be applied as a proxy measure of adiposity among slim males and among slim and overweight females, but not among the other groups.

\section{Introduction}

Obesity is perhaps the greatest nutritional problem in European countries (WHO, 1998). The proportion of obese adults has been steadily increasing (Monereo et al., 1997) in developing countries as well as in industrialized ones (Martorell et al., 1998). In this context, obesity is associated with an increased risk of all-cause mortality with many specific health consequences, including coronary heart disease, hypertension, diabetes mellitus, osteoarthritis and some kinds of cancers (Kiefer et al., 1998; Laitinen, 1998). The obesity distribution and prevalence is associated with gender, socioeconomic level and life-style factors such as diet habit or physical activity patterns (INCLEN 
Multicentre Collaborative Group, 1994; Murray \& Lopez, 1997; Day \& Varghese, 1994; MartínezGonzález et al., 1999; Martínez et al., 1999).

Self-reported body mass index (BMI) has been used in a number of surveys as a good correlate of the true measurement, although it is known that the weight is often underestimated and the height is overestimated (Stunkard \& Albaum, 1981; Stewart et al., 1987; Willett, 1998). Thus, some epidemiological studies concerning obesity have used perceived body image as a proxy indicator of body weight status (Madrigal et al., 1999), although they were first designed and used to identify self-esteem and body shape satisfaction in subjects with eating disorders (Davis et al., 1994; Thompson \& Gray, 1995; Gittelsohn et al., 1996; Stevens et al., 1997).

In order to decrease the cost and time spent on the prevalence studies, perceived body image may be thought as a suitable, although approximate, alternative to replace the direct assessment of weight and height. The purpose of this report was to identify those factors affecting the adequacy of self-classification into categories of BMI using body image perception among European Union citizens.

\section{Material and methods}

This project (A Pan-European Survey on Body Weight and Physical Activity) was established in
1997 when 15232 subjects, 7155 men and 8077 women, older than 15 years and living in the 15 European Union countries, were interviewed and responded to a previously developed questionnaire (Kearney et al., 1997). The selection of the sample was designed with the purpose of obtaining nationally representative samples from each member state, according to the standards of the marketing research set out by ICC/ESOMAR (European Society for Opinion and Marketing Research).

The questionnaire included issues about socioeconomic, demographic and anthropometric variables, as well as other questions related to attitudes and lifestyle, which was developed by an international group of experts in epidemiology, nutrition, statistics and sociological surveys. Information was obtained from direct interview. Each subject was personally contacted and a faceto-face interview was conducted in his/her own home by a professional interviewer specifically trained for this study, belonging to a specialized firm developing social surveys. The interviews were conducted as part of Eurobus, an international group of market research organizations.

Self-reported BMI was grouped into four categories using the cutpoints established by the WHO (1998), while body image (Fig. 1) was assigned into four categories using the classification recommended by the authors of the nine figures scheme (McElhone et al., 1999). Thus,

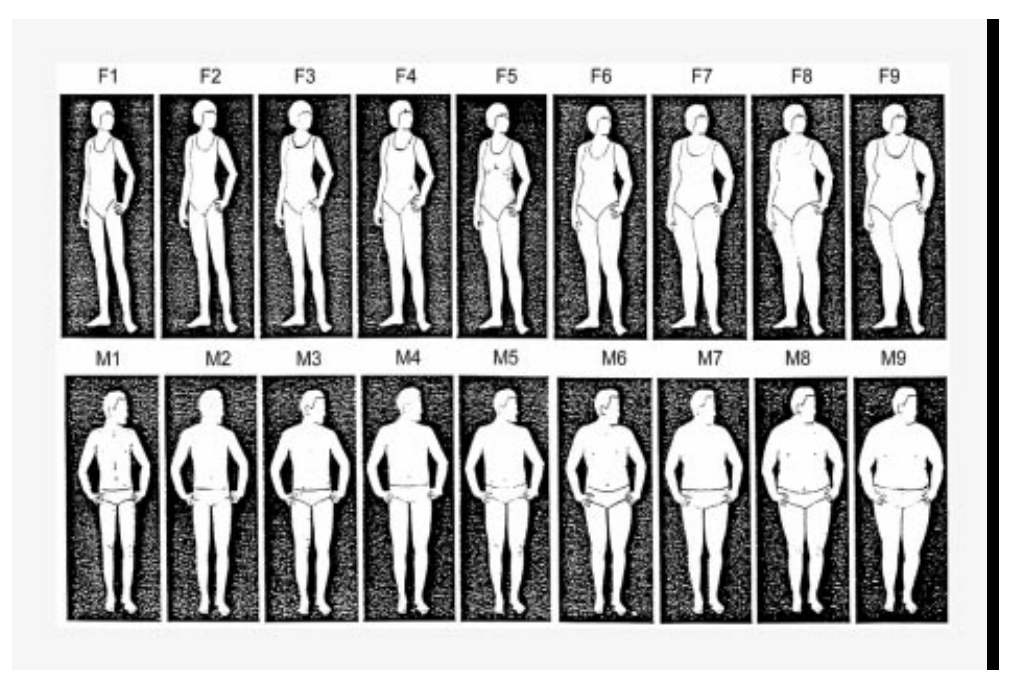

Figure 1 Options presented to select their silhouettes (McElhone et al., 1999). 
individuals were grouped according to the following criteria: pictures 1,2 and 3 as equivalent to underweight subjects $\left(B M I=19.99 \mathrm{~kg} \mathrm{~m}^{-2}\right)$, pictures 4 and 5 to represent normal weighted subjects $\left(B M I=20-24.99 \mathrm{~kg} \mathrm{~m}^{-2}\right)$, pictures 6 and 7 representing overweight subjects $(\mathrm{BMI}=$ 25-29.99 $\mathrm{kg} \mathrm{m}^{-2}$ ) and 8 and 9 represent obese subjects (BMI $=30 \mathrm{~kg} \mathrm{~m}^{-2}$ ).

To identify the appropriateness of the perception of body image using self-reported BMI as a criterion, proportions of participants who correctly self-classified were calculated according to each BMI category. This proportion was computed by dividing the number of individuals who agreed by the total number of individuals in that specific category. The $95 \%$ confidence intervals for each percentage, stratifying by gender, BMI and several socioeconomic variables, were calculated. The socioeconomic variables selected were: age, country (grouped in Mediterranean: Greece, Italy, Portugal and Spain; Central: Austria, Belgium, France, Germany, Ireland, Luxembourg, Netherlands and UK; or Scandinavian: Denmark, Finland and Sweden), education, economic level and number of children. Other variables related to attitudes were also considered: physical activity, hours/day sitting down, smoking, the stages of change for physical activity according to the model of change (Prochaska et al., 1992) and weight change during the last 6 months. Pearson $\chi^{2}$ was used to compare the proportion of participants who correctly perceived their own body image within each category of nominal variables, and a linear trend test was used to compare this proportion across categories of ordinal variables. In the multivariate analysis, separated logistic regression models for each gender were fitted to adjust for potentially confounding variables using the correctness of selfclassifying the own body image as the outcome. Odds ratios were used to estimate relative risks.

\section{Results}

The proportion of participants who correctly assessed their own body image was affected by sociodemographic variables (Table 1). Thus, women classified themselves better than men (57.6 vs. $32.7 \%, P<0.001)$. Within levels of BMI, the best classification was obtained among underweight individuals $(92.9 \%$ of adequate classification for men and $79.3 \%$ for women). Men classified themselves better if they were older $38.3 \%$ among those in the older stratum, $P<0.001$ for the linear trend test) and women if they were younger (60.0\%, $P<0.001)$. Men without sons/daughters and women with sons/daughters were the better categorized (33.6\% and 59.8\%, respectively). A better classification was achieved in participants from Scandinavian countries, for both men and women (34.2\% for men and 60.0 for women). Women who had the lowest socioeconomic level and the highest educational level were the best classified, with proportions of adequacy of 59.6\% and $60.4 \%$, respectively. However, no significant differences were found among men regarding their socioeconomic level, while in relation to educational level the best classification was found in the lowest level of literacy $(34.0 \%, P=0.04$ for linear trend).

The self-perception of body image was affected by attitudes and lifestyle variables (Table 2). Women who had lost weight in the last 6 months and men who had gained it were the best classified. (59.7\% and $35.9 \%$, respectively). Men and women who were former smokers tended to classify themselves better than current smokers or nonsmokers $(36.3 \%$ for men and 60.6 for women). Subjects in the 'contemplation' stage of physical activity tended more accurately to choose his/her actual image (36.6\% in men and $63.3 \%$ in women). Men who reported moderate activity (1-4 h week ${ }^{-1}$ ) and women who reported vigorous activity (more than $4 \mathrm{~h} \mathrm{week}^{-1}$ ) were the subjects with the best agreement between perceived body image and BMI $(34.6 \%$ and $58.7 \%$, respectively). Women who spent more than $4 \mathrm{~h} \mathrm{day}^{-1}$ sitting down presented a higher proportion of correct classification of 59.5\% $(P<0.001)$.

In absolute terms, the proportion of participants who were well classified using the perception of body image was small. Thus, we selected only those subjects who classified themselves incorrectly and analysed the misclassification trend by gender and within each self-reported BMI category (Fig. 2). Misclassified underweight subjects tended to choose a normal picture, 
Table 1 Percentage of participants who were correctly classified in categories of self-reported body mass index (BMI) according to their self-perception of body image

\begin{tabular}{|c|c|c|c|c|c|c|}
\hline & \multicolumn{3}{|l|}{ Male } & \multicolumn{3}{|c|}{ Female } \\
\hline & $n$ & $\%$ Correct & $P^{*}$ & $n$ & $\%$ Correct & $P^{*}$ \\
\hline Total sample & 7104 & 32.7 & & 8005 & 57.6 & $<0.001$ \\
\hline Current BMI & & & $<0.001$ & & & $<0.001$ \\
\hline Underweight (BMI $\leq 19.99$ ) & 424 & 92.9 & & 1214 & 79.3 & \\
\hline Normal (20-24.99) & 3442 & 26.5 & & 3852 & 51.3 & \\
\hline Overweight (25-29.99) & 2566 & 33.8 & & 2011 & 62.6 & \\
\hline Obesity $(\geq 30)$ & 628 & 24.2 & & 780 & 52.7 & \\
\hline Age & & & $<0.001$ & & & $<0.001$ \\
\hline $15-34$ & 2740 & 29.6 & & 2929 & 60.0 & \\
\hline $35-54$ & 2428 & 31.8 & & 2975 & 58.1 & \\
\hline$\geq 55$ & 1933 & 38.3 & & 2100 & 53.5 & \\
\hline Children & & & 0.024 & & & 0.001 \\
\hline No & 4838 & 33.6 & & 4926 & 56.2 & \\
\hline Yes & 2266 & 30.9 & & 3079 & 59.8 & \\
\hline Country & & & 0.011 & & & 0.033 \\
\hline Scandinavian & 1445 & 34.2 & & 1668 & 60.0 & \\
\hline Central & 3280 & 33.8 & & 3708 & 57.7 & \\
\hline Mediterranean & 2379 & 30.4 & & 2629 & 55.9 & \\
\hline Socio-economic level & & & 0.752 & & & 0.007 \\
\hline Low & 1174 & 33.0 & & 1209 & 59.6 & \\
\hline Mid-Low & 1844 & 32.9 & & 2002 & 59.1 & \\
\hline Mid-High & 2266 & 31.9 & & 2484 & 56.0 & \\
\hline High & 1413 & 34.1 & & 1789 & 55.8 & \\
\hline Educational level & & & 0.038 & & & $<0.001$ \\
\hline Primary & 2183 & 34.0 & & 2560 & 54.9 & \\
\hline Secondary & 3572 & 32.8 & & 4134 & 58.4 & \\
\hline University & 1334 & 30.5 & & 1292 & 60.4 & \\
\hline
\end{tabular}

* Pearson Chi-square for the comparison of the proportion of subjects who were correctly classified.

independently of gender (Fig. 2a). Misclassified normal men tended to choose pictures 1,2 or 3 . On the other hand, misclassified normal women tended to choose both slim and overweight pictures (Fig. 2b).

Overweight people, men and women, tended to choose normal figures, but obese figures were chosen more frequently by females than by males. Overweight men underestimated their weight, because the slim figure was approximately selected by $18 \%$ of them (Fig. 2 c). Obese men and women underestimated their weight and they classified themselves more often as overweight subjects (Fig. 2d).

After controlling for confounders (Table 3) we observed that the odds ratios of being well classified for slim (BMI $<20 \mathrm{~kg} \mathrm{~m}^{-2}$ ) women as compared with women with normal BMI $\left(20-25 \mathrm{~kg} \mathrm{~m}^{-2}\right.$ ) was 3.62 (95\% confidence inter$\mathrm{val}=3.06-4.29)$ and $1.62(95 \% \mathrm{CI}=1.43-1.84)$ for overweight women. Thus, slim and overweight women were more likely to better classify themselves through perceived body image.

The multivariate odds ratio of being well classified among women with children was 1.13 $(95 \% \quad \mathrm{CI}=1.02-1.26) \quad$ compared with women without them.

The proportion of well classified participants increased with higher number of hours sitting down during their leisure time. Women who reported $1-4 \mathrm{~h} \mathrm{day}^{-1}$ sitting down had an odds ratio of 1.38 (95\% CI $=1.12-1.69)$ compared with women who reported less than $1 \mathrm{~h}$ of sitting down during leisure time. The odds of being correctly classified increased to 1.47 (95\% CI $=1.19-1.81)$ for women who reported more than $4 \mathrm{~h}^{\text {day }}{ }^{-1}$ sitting down. 
Table 2 Percentage of participants who were correctly classified in categories of self-reported body mass index (BMI) according to their self-perception of body image

\begin{tabular}{|c|c|c|c|c|c|c|}
\hline & \multicolumn{3}{|l|}{ Male } & \multicolumn{3}{|c|}{ Female } \\
\hline & $n$ & $\%$ Correct & $P^{*}$ & $n$ & $\%$ Correct & $P^{*}$ \\
\hline \multicolumn{3}{|l|}{ Change in weight } & 0.001 & & & 0.156 \\
\hline Gained weight & 1347 & 35.9 & & 1983 & 58.1 & \\
\hline Lost weight & 953 & 35.7 & & 1453 & 59.7 & \\
\hline Stayed the same weight & 4648 & 31.3 & & 4405 & 56.9 & \\
\hline \multicolumn{3}{|l|}{ Smoking } & 0.011 & & & 0.001 \\
\hline Smoker & 2768 & 31.3 & & 2360 & 60.0 & \\
\hline Ex-smoker & 1108 & 36.3 & & 791 & 60.6 & \\
\hline Non-smoker & 3205 & 32.7 & & 4831 & 55.9 & \\
\hline \multicolumn{3}{|c|}{ Stage of change regarding physical activity } & $<0.001$ & & & $<0.001$ \\
\hline Precontemplation & 1860 & 36.2 & & 2303 & 56.6 & \\
\hline Contemplation & 817 & 36.6 & & 1103 & 63.3 & \\
\hline Decision & 563 & 33.6 & & 817 & 58.1 & \\
\hline Action & 314 & 31.8 & & 400 & 60.5 & \\
\hline Maintenance & 2518 & 29.5 & & 2070 & 57.4 & \\
\hline Relapse & 671 & 31.9 & & 791 & 55.9 & \\
\hline \multicolumn{3}{|l|}{ Physical activity } & 0.011 & & & 0.006 \\
\hline No activity & 1793 & 34.0 & & 2364 & 54.8 & \\
\hline $1-4$ h week $^{-1}$ & 2091 & 34.6 & & 2572 & 58.5 & \\
\hline$>4 \mathrm{~h} \mathrm{week}^{-1}$ & 2980 & 30.8 & & 2746 & 58.7 & \\
\hline \multicolumn{3}{|l|}{ Hours/day sitting down } & 0.07 & & & $<0.001$ \\
\hline$<1 \mathrm{~h}$ & 498 & 31.1 & & 555 & 50.3 & \\
\hline $1-4 \mathrm{~h}$ & 3505 & 32.0 & & 4426 & 57.4 & \\
\hline$>4 \mathrm{~h}$ & 3062 & 33.9 & & 2968 & 59.5 & \\
\hline
\end{tabular}

* Pearson Chi-square for the comparison of the proportion of subjects who were correctly classified.

In the case of men, Central European men had an increased odds ratio, $1.22(95 \% \mathrm{CI}=1.07-1.39)$ as compared to Mediterranean men. Scandinavian men had an odds ratio of $1.28 \quad(95 \%$ $\mathrm{CI}=1.08-1.51)$ compared to Mediterranean men.

An increasing number of hours spent on exercise was inversely related to the probability of a correct perception of the body image (Table 4). For men who spent more than $4 \mathrm{~h}$ per week on physical activity, the odds ratio was 0.78 (95\% $\mathrm{CI}=0.68-0.91$ ).

The multivariate odds ratios of being correctly classified among men who gained weight or who lost it in the last 6 months were $1.41 \quad(95 \%$ $\mathrm{CI}=1.22-1.64)$ and $1.26(95 \% \mathrm{CI}=1.06-1.44)$, respectively, as compared with men who stayed at the same weight.

Age slightly modified the association between self-reported BMI and the adequate perception of body image. Among men with BMI of less than
$20 \mathrm{~kg} \mathrm{~m}^{-2}$ the multivariate adjusted odds ratio compared to men in the normal range was 9.12 (95\% CI $=7.50-11.09)$ for younger men (15-34 years), $7.56 \quad(95 \% \quad \mathrm{CI}=5.54-10.31)$ for middle-aged men (35-54 years) and 5.60 (95\% $\mathrm{CI}=10.77-70.71)$ for older men. BMI of 30 or more was not significantly associated with the probability of being correctly classified except in the case of middle-aged obese men. Obese men with respect to normal-weighted men had odd ratios of $0.79(95 \% \mathrm{CI}=0.59-1.06), 0.77(95 \%$ $\mathrm{CI}=0.62-0.94)$ and $1.11 \quad(95 \% \mathrm{CI}=0.89-1.38)$, within the strata of $15-34,35-54$ and $\geqslant 55$ years of age, respectively.

The probability of being well classified was about double in women as compared to men except in the underweight category. Slim women were more likely to be well classified. On the other hand, the self-reported BMI was the more important variable to predict the probability of a 

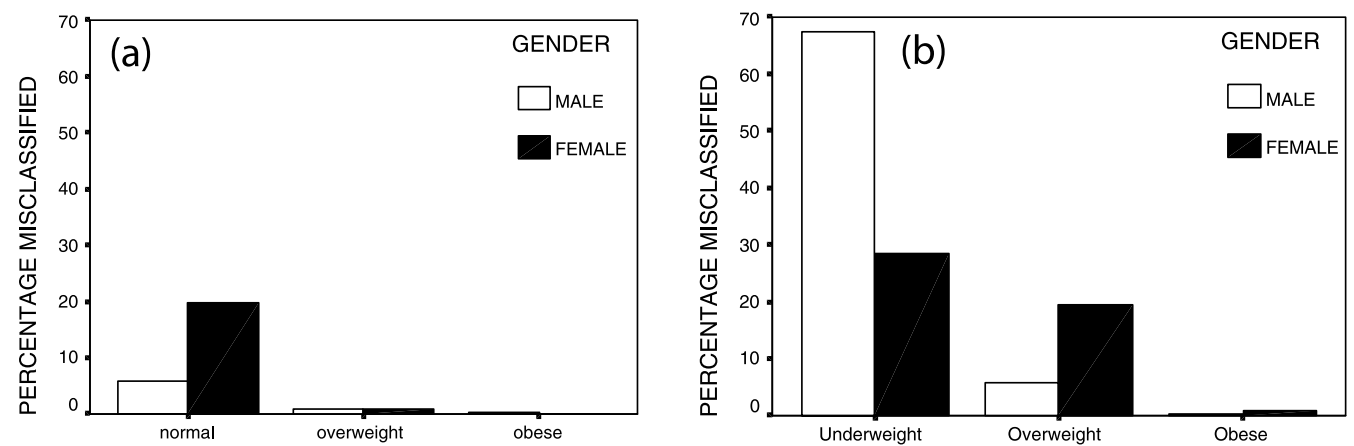

Body Image

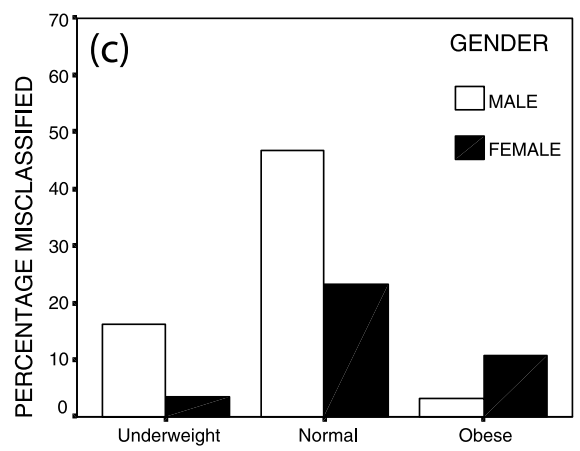

Body Image

Body Image

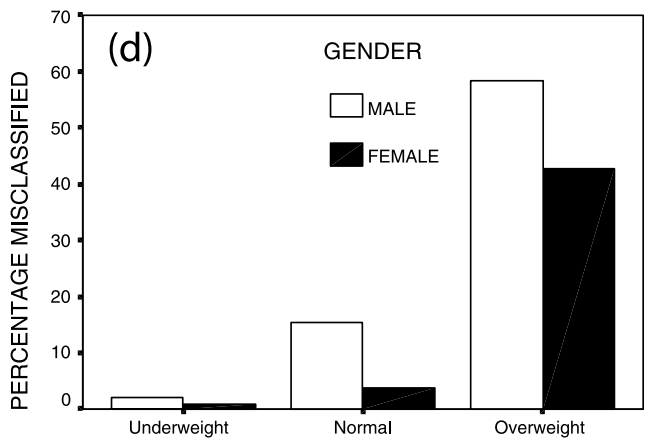

Body Image

Figure 2 Misperceptions of body image according to gender and self-reported BMI. Percentage of misclassified subjects who choose each incorrect body image. Distribution of body image misperception by gender among (a) underweight people, (b) normal people, (c) overweight people, (d) obese people.

\begin{tabular}{lrlrr}
\hline & $n$ & OR & $95 \% \mathrm{Cl}$ & $P$ \\
\hline BMI (kg m $\left.{ }^{-2}\right)$ & & & & \\
$\quad$ Normal (20-24.99) & 3149 & 1 (ref) & & \\
$\quad$ Underweight (= 19.99) & 994 & 3.62 & $3.06-4.29$ & $<0.001$ \\
$\quad$ Overweight (25-29.99) & 1594 & 1.62 & $1.43-1.84$ & $<0.001$ \\
$\quad$ Obesity (= 30) & 615 & 1.05 & $0.88-1.25$ & 0.57 \\
Children & & & & \\
$\quad$ No & 3841 & 1 (ref) & & \\
$\quad$ Yes & 2511 & 1.13 & $1.02-1.26$ & 0.02 \\
Hours/day sitting down & & & & \\
$\quad$ None & 427 & 1 (ref) & & \\
$\quad$ 1-4 h & 3575 & 1.38 & $1.12-1.69$ & 0.003 \\
$>4$ h & 2350 & 1.47 & $1.19-1.81$ & $<0.001$ \\
\hline
\end{tabular}

Table 3 Odds ratios (95\% confidence intervals) in the logistic regression model of being well classified into self-reported BMI categories according to perceived body image (dependent variable) among women

A higher odds ratio means a higher probability of someone correctly classifying his/her body image according to self-reported BMI categories.

correct self-classification of BMI based on the perception of body image. Underweight subjects, independently of gender, had more probability of agreement compared with subjects in a normal category of BMI.

\section{Discussion}

The high prevalence of obesity is an important problem concerning public health professionals. Thus, some research has tried to identify causal 
Table 4 Odds ratios (95\% confidence intervals) in the logistic regression model of being well classified into self-reported BMI categories according to perceived body image (dependent variable) among men

\begin{tabular}{|c|c|c|c|c|}
\hline & $n$ & OR & $95 \% \mathrm{Cl}$ & $P$ \\
\hline \multicolumn{5}{|l|}{ Country } \\
\hline Mediterranean & 2009 & 1 (ref) & & \\
\hline Central & 2754 & 1.22 & $1.07-1.39$ & 0.004 \\
\hline Scandinavian & 1169 & 1.28 & $1.08-1.51$ & 0.004 \\
\hline \multicolumn{5}{|l|}{ Physical activity } \\
\hline No activity & 1386 & 1 (ref) & & \\
\hline $1-4$ h week $^{-1}$ & 1878 & 0.99 & $0.85-1.17$ & 0.92 \\
\hline$>4 \mathrm{~h} \mathrm{week}^{-1}$ & 2668 & 0.78 & $0.68-0.91$ & 0.002 \\
\hline \multicolumn{5}{|l|}{ Change in weight } \\
\hline Stayed the same weight & 3960 & 1 (ref) & & \\
\hline Gained weight & 1166 & 1.41 & $1.22-1.64$ & $<0.001$ \\
\hline Lost weight & 806 & 1.26 & $1.06-1.44$ & 0.009 \\
\hline \multicolumn{5}{|l|}{ Age $\times$ BMI } \\
\hline \multicolumn{5}{|l|}{$15-34$} \\
\hline Normal & 1418 & 1 (ref) & & \\
\hline Underweight & 253 & 9.12 & 7.50-11.09 & $<0.001$ \\
\hline Overweight & 544 & 1.10 & $0.94-1.29$ & 0.23 \\
\hline Obese & 100 & 0.79 & $0.59-1.06$ & 0.11 \\
\hline \multicolumn{5}{|l|}{$35-54$} \\
\hline Normal & 878 & 1 (ref) & & \\
\hline Underweight & 73 & 7.56 & $5.54-10.31$ & $<0.001$ \\
\hline Overweight & 852 & 0.99 & $0.86-1.13$ & 0.86 \\
\hline Obese & 222 & 0.77 & $0.62-0.94$ & 0.012 \\
\hline \multicolumn{5}{|l|}{$\geq 55$} \\
\hline Normal & 601 & 1 (ref) & & \\
\hline Underweight & 45 & 5.60 & 10.77-70.71 & $<0.001$ \\
\hline Overweight & 752 & 1.60 & $1.36-1.87$ & $<0.001$ \\
\hline Obese & 194 & 1.11 & $0.89-1.38$ & 0.38 \\
\hline
\end{tabular}

A higher odds ratio means a higher probability of someone correctly classifying his/her body image according to self-reported BMI categories. factors and social, economic or attitudinal characteristics relative to obesity (Martínez et al., 1999). Also, unhealthy life-styles have been observed because these behaviours appear to contribute to the great prevalence of obesity (Jeffery, 1996; Cachelin et al., 1998). Their knowledge is essential for establishing strategies of prevention and treatment (White, 1992a,b; Sisson et al., 1997).

Most studies would agree that obesity prevalence is a more serious problem among women than among men; it increases with age, is more common in lower social classes, especially in developing countries and in black women (Riley et al., 1998). Simultaneously, newer indicators are looked for to simplify the studies and to decrease their cost, time and effort. For that reason, the use of validated self-reported BMI is increasing as an alternative for the direct measurement of weight and height. (Stunkard \& Albaum, 1981; Willett,
1998). The use of self-reported relative weight measures as a continuous covariate would have little effect on analyses (Stewart et al., 1987). Therefore, in this survey the self-reported BMIs have been used. In large studies, it is often not convenient to use the more accurate 'gold standard' (direct measurement of weight and height) to calculate the BMI. Unfortunately, we did not collect direct information about BMI and we had to rely on self-reported data. We acknowledge that the comparison of two subjective assessment methods has inherent limitations. However, it is known that the correlation between BMI directly computed from the measurement of weight and height and self-reported BMI is adequate (Willett, 1998). Moreover, in many analytical epidemiological studies, self-reported BMI has been shown to be an important predictor of different diseases (Manson et al., 1990; Carey et al., 1997). 
Frequently, variables such as the perception of body image, which were previously employed in other types of studies, are also incorporated to epidemiological studies of chronic diseases in order to improve the population description. The body image can be applied to identify self-esteem and satisfaction level in patients with eating disorders (Thompson et al., 1991; Grilo et al., 1994).

In this report it has been attempted to replace body image for self-reported BMI and identify those factors affecting the degree of misclassification, which can appear when using the perceived body image instead of self-reported BMI. If selfdeclared weight and height has a satisfactory confidence level (Palta et al., 1982), it could be expected that the pattern referring to body image was the same. Thus, it has been hypothesized that body image could be used as a proxy estimate of nutritional status.

Some previous reports are based on the identification of differences in perception of body image by gender (Fallon \& Rozin, 1985; Brodie et al., 1991), by ethnic and social differences (Furnham \& Baguma, 1994; Caldwell et al., 1997; Ogden \& Elder, 1998), or are restricted to obese populations (Hill \& Williams, 1998). Furthermore, some authors have investigated the problem of the low self-esteem and the low body shape satisfaction (Goldberg et al., 1996), while others have reported the relationship of body image and BMI in some disorders such as anorexia nervosa and bulimia nervosa to detect the prevalence among preadolescents, adolescents and young adults (Sciacca et al., 1991; Schulken et al., 1997; Kennet \& Nisbet, 1998).

Also, a measurement bias in the analysis of an adequate perception of body image can be introduced because in younger and middle-aged populations in which weight change primarily reflects gain or loss of fat mass, BMI is strongly correlated with fat mass adjusted for height. However, in older persons, changes in BMI reflect a combination of many factors including true gain or loss of fat mass, and weight changes due to the loss of lean body mass. Therefore, the interpretation of BMI among an older population may be more complex than, and not necessarily comparable with, similar BMI among younger populations.
Furthermore, if we use self-reported BMI, instead of a calculated one, measurement bias is increased.

The information obtained differed from some of those studies because of the characteristics of the surveyed population or because of the study design. This study was based on a representative sample of all the Member States of the European Union. It included 7104 men and 8005 women, with an age of 15 years or more. Thus, there is only a limited possibility of comparison with our results. Only one study (Leonhard \& Barry, 1998) has a similar aim, but the results differed, showing that the ability to obtain a good classification was higher for men than for women. Those researchers also used, as we have done, the nine male and nine female thin-to-heavy figure silhouette drawings. Discrepancy scores were significantly different for groups of females. Normal-weight women could not consistently estimate their size, while obese and very obese females underestimated their size.

The use of the body image among European Union citizens has different validity depending on sociodemographic or attitudinal categories. Our results reveal that slimmer women tended to classify themselves better than men. This methodological strategy could have a better validity to identify individuals within this category. On the other hand, the physical activity level is inversely related to the degree of being well classified. Women classified themselves better if they spent more than $4 \mathrm{~h}$ sitting down and men if their physical activity was greater than $4 \mathrm{~h}$ per week. Geographical differences occurred, with Scandinavian inhabitants classifying themselves better. In addition, middle-age obese men of the Member States of the European Union had the lowest probability of a correct classification because this group is apparently not conscious of their body shape nor of potential problems associated with their BMI. In general terms, our findings involving cross-country, socioeconomic, gender or age differences have also been reported using other approaches (WHO, 1998).

Thus, the use of the perceived body image as an estimate of the nutritional status could be difficult in an individualized application, mostly in men. In the best case, it should be used cautiously and only among slim men and among slim and overweight 
women. Thus, designs of actions of health promotion related to obesity ought to consider different patterns by gender.

Summing up, the use of body image as an estimate of nutritional status and specifically the degree of adiposity is inadequate among European Union citizens. Body image would be valid only in approximately $30 \%$ of men and $60 \%$ of women. However, in underweight individuals (males and females) it had great validity. Combination of this estimate with other measures such as the waist circumference and waist/hip ratio can be a better indicator of risk associated with obesity than perceived body image.

\section{Acknowledgments}

The financial support from the IEFS from Ireland and from European Union (Directorate V) is gratefully acknowledged.

\section{References}

Brodie, D.A., Slade, P.D. \& Riley, V.J. (1991) Sex differences in body-image perceptions. Percept. Mot. Skills. 72, 73-74.

Cachelin, F.M., Striegel, R.H. \& Elder, K.A. (1998) Realistic weight perception and body size assessment in a racially diverse community sample of dieters. Obes. Res. 6, $62-68$.

Caldwell, M.B., Brownell, K.D. \& Wilfley, D.E. (1997) Relationship of weight, body dissatisfaction, and selfesteem in African American and white female dieters. Int. J. Eat. Disord. 22, 127-130.

Carey, V.J., Walters, E.E., Colditz, G.A., Solomon, C.G., Willett, W.C., Rosner, B.A., Speizer, F.E. \& Manson, J.E. (1997) Body fat distribution and risk of non-insulindependent diabetes mellitus in women. Am. J. Epidemiol. 145, 614-619.

Davis, C., Durnin, J.V., Dionne, M. \& Gurevich, M. (1994) The influence of body fat content and bone diameter measurements on body dissatisfaction in adult women. Int. J. Eat. Disord. 15, 257-263.

Day, E.N. \& Varghese, C. (1994) Oesophageal cancer. Cancer Surv. 19, 43-54.

Fallon, A.E. \& Rozin, P. (1985) Sex differences in perceptions of desirable body shape. J. Abnormal Psychol. 94, 102-105.

Furnham, A. \& Baguma, P. (1994) Cross-cultural differences in the evaluation of male and female body shapes. Int. J. Eat. Disord. 15, 81-89.
Gittelsohn, J., Harris, S.B., Lyman, T.H., Hanley, A., Barnie, A. \& Zinman, B. (1996) Body image concepts differ by age and sex in an Ojibway-Cree Community in Canada. J. Nutr. 126, 2990-3000.

Goldberg, J.P., Bailey, S.M., Lenart, E.B. \& Koff, E. (1996) A new visual image rating scale for females: correlations with measures of relative fatness, weight dissatisfaction and body-esteem. Percept. Mot. Skills 82, 1075-1084.

Grilo, C.M., Wilfley, D.E., Brownell, K.D. \& Rodin, J. (1994) Teasing, body image, and self-esteem in a clinical sample of obese women. Addict. Behav. 19, 443-450.

Hill, A.J. \& Williams, J. (1998) Psychological health in a non-clinical sample of obese women. Int. J. Obes Relat Metab Disord. 22, 578-583.

INCLEN Multicentre Collaborative Group. (1981) Socioeconomic status and risk for cardiovascular disease: a multicentre collaborative study in the International Clinical Epidemiology Network (INCLEN). J. Clin. Epidemiol. 47, 1401-1409.

Jeffery, R.W. (1996) Bias in reported body weight as a function of education, occupation, health and weight concern. Addict. Behav. 21, 217-222.

Kearney, M., Kearney, J.M. \& Gibney, M.J. (1997) Methods used to conduct the survey on consumer attitudes to food, nutrition and health on nationally representative samples of adults from each member state of the European Union. Eur. J. Clin. Nutr. 51, S3-S7.

Kennet, D.J. \& Nisbet, C. (1998) The influence of body mass index and learned resourcefulness skills on body image and lifestyle practises. Patient. Educ. Couns. 33, 1-12.

Kiefer, I., Kunze, U., Mitsche, N. \& Kunze, M. (1998) Obesity in Austria: epidemiologic and social medicine aspects. Acta Med. Austr. 25, 126-128.

Laitinen, J. (1998) Obesity is a health problem. Int. J. Circumpolar Health 57, 104-108.

Leonhard, M.L. \& Barry, N.J. (1998) Body image and obesity: effects of gender and weight on perceptual measures of body image. Addict. Behav. 23, 31-34.

Madrigal, H., Irala, J., Martínez-González, M.A., Kearney, J., Gibney, M. \& Martínez, J.A. (1999) Percepción de la imagen corporal como aproximación cualitativa al estado de nutrición. Salud Pública Mex. 41, 479-486.

Manson, J.E., Colditz, G.A., Stampfer, M.J., Willett, W.C., Rosner, B., Monson, R.R., Speizer, F.E. \& Hennekens, C.H. (1990) A prospective study of obesity and risk of coronary heart disease in women. N. Engl. J. Med. 322, 882-889.

Martínez, J.A., Kearney, J.M., Kafatos, K., Paquet, S. \& Martínez-González, M.A. (1999) Variables independently associated with self-reported obesity (BMI $>30 \mathrm{~kg} /$ $\mathrm{m} 2$ ) in the European Union population. Public Health Nutr. 1, 125-133.

Martínez-González, M.A., Martínez, J.A., Hu, F.B., Gibney, M.J. \& Kearney, J.M. (1999) Physical inactivity, sedentary lifestyle and obesity in the European Union. Int. J. Obes. Relat. Metab. Disord. 23, 1192-1201. 
Martorell, R., Khan, L.K., Hughes, M.L. \& GrummerStrawn, L.M. (1998) Obesity in Latin American women and children. J. Nutr. 128, 1464-1473.

McElhone, S., Kearney, J.M., Giachetti, I., Zunft, H.F. \& Martinez, J.A. (1999) Body image perception in relation to recent weight changes and strategies for weight loss in a nationally representative sample in the European Union. Public Health Nutr. 2, 143-151.

Monereo, S., Durán, M.A., Elviro, R. \& Alvarez, J. (1997) Epidemiología de la obesidad. In Obesidad Presente y futuro. eds B. Moreno, S. Monereo, J. Alvarez. pp. 85-94. Madrid, MA: Grupo Aula Médica, S.A.

Murray, C.J. \& Lopez, A.D. (1997) Global mortality, disability and contribution of risk factors. Global Burden of Disease Study. Lancet. 349, 1436-1442.

Ogden, J. \& Elder, C. (1998) The role of family status and ethnic group on body image and eating behavior. Int. J. Eat. Disord. 23, 309-315.

Palta, M., Prineas, R.J., Berman, R. \& Hanan, P. (1982) Comparison of self-reported and measured height and weight. Am. J. Epidemiol. 115, 223-230.

Prochaska, J.D., Norcross, J.C. \& Fowler, J.L. (1992) Attendance and outcome at work control program: processes and stages of change as process and predictor variables. Addict. Behav. 17, 35-45.

Riley, N.M., Bild, D.E., Cooper, L., Schreiner, P., Smith, D.E., Sorlie, P. \& Thompson, J.K. (1998) Relation of selfimage to body size and weight loss attempts in black women. The CARDIA Study. Am. J. Epidemiol. 148, 1062-1068.

Schulken, E.D., Pinciaro, P.J., Sawyer, R.G., Jensen, J. \& Hoban, M.T. (1997) Sorority women's body size perceptions and their weight-related attitudes and behaviors. J. Am. Coll. Health. 46, 69-74.

Sciacca, J.P., Melby, C.L., Hyner, G.C., Brown, A.C. \& Femea, P.L. (1991) Body Mass Index and perceived weight status in young adults. J. Community Health 16, 159-168.
Sisson, B.A., Franco, S.M., Carlin, W.M. \& Mitchell, C.K. (1997) Body fat analysis and perception of body image. Clin. Pediatr. 36, 415-418.

Stevens, J., Kumaylka, S.H. \& Keil, J. (1997) Attitudes toward body size and dieting. Differences between elderly black and white women. Am. J. Public Health. 84, 1322-1325.

Stewart, A.W., Jackson, M.A., Ford, M.A. \& Beaglehole, R. (1987) Underestimation of relative weight by use of self-reported height and weight. Am. J. Epidemiol. 125, 122-126.

Stunkard, A.J. \& Albaum, J.M. (1981) The accuracy of self reported weights. Am. J. Clin. Nutr. 34, 1593-1599.

Thompson, J.K., Fabian, L.J., Moulton, D.O., Dunn, M.E. \& Altabe, M.N. (1991) Development and validation of physical appearance related teasing scale. J. Pers. Assess. 56, 513-521.

Thompson, M.A. \& Gray, J.J. (1995) Development and validation of a new body image assessment scale. J. Pers. Assess. 64, 258-269.

White, J.H. (1992a) Women and eating disorders. Part II: Developmental, familial, and biological risk factors. Health Care Women Int. 13, 363-373.

White, J.H. (1992b) Women and eating disorders. Part I: Significance and sociocultural risk factors. Health Care Women Int. 13, 351-362.

WHO. (1998) Obesity preventive and managing the global epidemiol. Report of a WHO consultation on Obesity. Geneve.3-5 June, 1997. Division of Noncomunicable Disease, Programme of Nutrition Family and Reproductive Health. Geneva: WHO.

Willett, W., ed. (1998) Anthropometric measures and body composition. In Nutrition and Epidemiology, 2nd edn. pp. 244-272. New York: Oxford University Press. 